\title{
Bone Loss in Ankylosing Spondylitis: Does Syndesmophyte Formation Have an Influence on Bone Density Changes?
}

\author{
Arzu Kaya Salih Ozgocmen Ayhan Kamanli Ozge Ardicoglu \\ Division of Rheumatology, Department of Physical Medicine and Rehabilitation, Faculty of Medicine, \\ Firat University, Elazig, Turkey
}

\section{Key Words}

Ankylosing spondylitis • Bone mineral density •

Syndesmophyte

\begin{abstract}
Objective: The aim of this study was to assess bone mineral density (BMD) using dual-energy $\mathrm{X}$-ray absorptiometry (DXA) in a group of patients with ankylosing spondylitis (AS) and the factors which have an impact on bone mass. Also, a subgroup of patients not treated with anti-osteoporotic or disease-modifying anti-rheumatic drugs was followed for 24 months to assess potential influencing factors on BMD changes. Subjects and Methods: Fifty-five patients (42 males, 13 females) with AS were enrolled in the study. Clinical examinations were performed. BMD was measured using DXA at lumbar spine (L2-L4) and proximal femur (femur neck BMD and total femur BMD). Lumbar spine radiographs were scored using the Stoke Ankylosing Spondylitis Spine Score (SASSS). Twenty-one of 55 patients who completed 24 months of follow-up without using the aforementioned medications were reassessed. Results: Active patients (Bath Ankylosing Spondylitis Disease Activity Index $>4, n=22$ ) had significantly lower femur neck and total BMD compared to inactive patients $(n=33)$, whereas spinal BMD was not different. Follow-up data revealed a $3.4 \%$ increase in spinal BMD but $0.9 \%$ and $0.25 \%$ decreases in femur neck BMD and total femur BMD, respectively. Percent changes in BMD mea-
\end{abstract}

surements and SASSS scores were not significantly different between active $(n=10)$ and inactive $(n=11)$ patients. Conclusion: Significant increase in spinal BMD in parallel with increased SASSS revealed that spinal involvement prominent with new bone formation, sclerosis and syndesmophytes may influence spinal BMD measurements using DXA methods in AS. Proximal femur measurements seem to be less affected from disease-related new bone formation.

Copyright $\odot 2009$ S. Karger AG, Basel

\section{Introduction}

Ankylosing spondylitis (AS) is a chronic inflammatory disease characterized by inflammation of the entheses of the axial and peripheral skeleton, which may lead to local bony erosions or regional osteopenia and further healing with sclerosis and new bone formation. Chronic inflammation and related mediators possibly provoke osteoporosis, which has been well-recognized in AS patients [1-7]. However the disease itself has a characteristic of not only reduced but also increased bone formation, which contributes to syndesmophyte formation and joint ankylosis, particularly in advanced disease.

Dual-energy X-ray absorptiometry (DXA) is a practical and safe method and is accepted as routine for measuring bone mineral density (BMD) [8]. However, this method has some limitations, particularly related to pro-

\section{KARGER}

Fax +4161306 1234

E-Mail karger@karger.ch

www.karger.com (c) 2009 S. Karger AG, Basel

1011-7571/09/0186-0470\$26.00/0

Accessible online at:

www.karger.com/mpp
Dr. Arzu Kaya

Firat Universitesi Hastanesi, FTR AD, Romatoloji BD

TR-23119 Elazig (Turkey)

Tel. +90 4242333555 ext. 2032, Fax +90 4242480509

E-Mail drarzukaya26@hotmail.com 
jection: spinal measurements in AS patients may be artificially increased as a consequence of ligamentous calcifications or sclerosis of the vertebral margins or end plates $[1,4,6]$.

Previous studies showed changes in bone mineral density (BMD) in AS using DXA methods [1-7]; however, it is quite important to show changes in BMD in longitudinal design, particularly paying attention to the disease outcome during the follow-up period. In this study we planned to follow up patients for 2 years and re-analyze subgroups who maintained a Bath Ankylosing Spondylitis Disease Activity Index (BASDAI) score less than or more than 4 during this period. This is the major difference of our study compared to the previous studies, which give the longitudinal results regardless of disease flare or remission during the course of follow-up.

The aim of this study was to assess BMD using DXA in a group of patients with AS and the factors which have an impact on bone mass. Also, a subgroup of patients who were not treated with anti-osteoporotic or disease-modifying anti-rheumatic drugs (DMARDs) was followed for 24 months to assess weighted factors on BMD changes.

\section{Subjects and Methods}

\section{Patients}

The study group consisted of 55 patients ( 42 males, 13 females) with AS who fulfilled modified New York criteria for the classification of AS [9]. All patients attending our outpatient clinic from primary care facilities were consecutively recruited. Exclusion criteria were patients with any other form of spondyloarthropathy (including AS secondary to inflammatory bowel disease or psoriasis), or had a history of neuroendocrine disorders (thyroid or parathyroid disorders, anticonvulsant usage, etc.), chronic renal or liver diseases, systemic high-dose corticosteroid usage, excessive alcohol intake. Clinical assessment included demographic data (age, gender, height, weight, body mass index in $\mathrm{kg} / \mathrm{m}^{2}$ ) and patients were assessed for normal vitamin D status. Disease duration was defined as the time elapsed between the onset of first disease-related symptom and enrollment. Patients' detailed drug histories were obtained. All the women included in the study were premenopausal.

Patients were taking various drug treatments at the time of the baseline measurements, as follows: 13 patients were taking nonsteroid anti-inflammatory drugs (NSAIDs), 5 sulfasalazine (SLZ), 4 methotrexate (MTX), 3 SLZ + MTX, 14 combination of SLZ or MTX with NSAIDs, and 16 were drug-free. Patients were examined by the same researcher (A.K.) after providing written informed consent. Clinical examination and measurements of functional ability and disease activity were carried out. Routine anthropometric measurements consisted of chest expansion, lumbar Schober test, finger-to-floor distance, and occiput-to-wall distance. Peripheral joint involvement was noted. BASDAI [10], the Health Assessment Questionnaire - Spondyloarthropathies, and the Bath Ankylosing Spondylitis Functional Index (BASFI) were performed $[11,12]$. BASDAI is a composite index and a widely used subjective measure of disease activity that has been valid, reproducible and responsive to change. This index evaluates disease activity using a composite measure of fatigue, axial and peripheral pain, stiffness and enthesopathy. The cut point for disease activity is accepted as a score of 4 [10]. Patient's global assessment of disease activity and pain in the last 2 days was measured on a $0-10 \mathrm{~cm}$ visual analogue scale (VAS-global). Erythrocyte sedimentation rate (ESR; Westergren method) and C-reactive protein (CRP; nephelemetric method, $\mathrm{mg} / \mathrm{l}$ ) were also measured.

Patients were classified as having active disease or inactive disease/low activity regarding BASDAI scores $\geq 4$ or $<4$. All 55 patients were followed for 24 months, and 21 of these $(13$ males, 8 females) who did not use disease-modifying anti-rheumatic drugs or other drugs that interfered with bone metabolism and maintained a mean BASDAI score $\geq 4$ or $<4$ throughout the 24 months of follow up were analyzed for clinical, laboratory and BMD measurements.

\section{Bone Mineral Density Measurements}

Diagnosis of osteoporosis in patients was based on WHO criteria established for osteoporosis in women ( $\mathrm{T}$ scores less than -2.5 in one region in lumbar spine or proximal femur) [8]. Male patients were also categorized using the same criteria since there is still no internationally accepted consensus for osteoporosis in men. Lumbar spine (anterior-posterior) and proximal femur BMD were measured using DXA on a Lunar DPX densitometer (Lunar, Madison, Wisc., USA). Values for results of DXA measurements were expressed as BMD $\left(\mathrm{g} / \mathrm{cm}^{2}\right)$ and T score of young adult healthy reference population, as supplied by the manufacturer (Lunar). Short-term precision for spine and femur neck measurements had a coefficient of variation of 2.1 to $2.3 \%$. A significant change in DXA was defined as greater than percent coefficient of variation $(2.8 \times$ precision of the measurement).

Study groups were classified according to the following criteria: normal $=$ patients whose $\mathrm{T}$ score was $\geq 1$ SD on $\mathrm{L} 2-4$, femur neck or total femur with normal BMD; osteopenia = patients with $\mathrm{T}$ score in these regions between -1 and $-2.5 \mathrm{SD}$; osteoporosis $=$ patients with T score on L2-4, femur neck or total femur less than $-2.5 \mathrm{SD}$.

\section{Radiological Scoring}

Lumbar lateral radiographs were scored using a detailed scoring method assessing the corners of the vertebrae by the same clinician (S.O.). The Stoke AS Spinal Score (SASSS) included the anterior and posterior sites of each lumbar vertebra [13]. Each corner was scored for the presence of squaring, sclerosis, erosions, syndesmophytes and bridging syndesmophytes. The maximal score was 72 . For the longitudinal study this scoring was executed for the lumbar spine radiographs taken at baseline and after 24 months.

Fasting blood samples were obtained, and sera were submitted for routine biochemical analysis, including total calcium and alkaline phosphatase, and inorganic phosphate, determined by chemiluminescence (Immulyte 2000; DPC, Los Angeles, Calif., USA), and vitamin D metabolite 25-hydroxyvitamin D (25(OH)D; Chromysystems Instruments and Chemicals, Munich, Germany), using high performance liquid chromatography. 
Table 1. Patient groups and clinical and demographic data

\begin{tabular}{|c|c|c|c|c|}
\hline & Total $(\mathrm{n}=55)$ & Inactive $(\mathrm{n}=33)$ & Active $(\mathrm{n}=22)$ & $\mathrm{p}$, active vs. inactive \\
\hline Age, years & $35.82 \pm 10.51$ & $37.39 \pm 10.99$ & $33.45 \pm 9.49$ & 0.203 \\
\hline Height, $\mathrm{cm}$ & $167.91 \pm 8.38$ & $169.03 \pm 8.74$ & $166.23 \pm 7.70$ & 0.158 \\
\hline Weight, kg & $66.10 \pm 12.17$ & $67.77 \pm 12.75$ & $63.59 \pm 11.05$ & 0.238 \\
\hline $\mathrm{BMI}, \mathrm{kg} / \mathrm{m}^{2}$ & $23.36 \pm 3.46$ & $23.61 \pm 3.52$ & $22.97 \pm 3.42$ & 0.358 \\
\hline Disease duration, years & $11.05 \pm 8.21$ & $11.85 \pm 9.04$ & $9.86 \pm 6.81$ & 0.612 \\
\hline Chest expansion, $\mathrm{cm}$ & $3.89 \pm 1.65$ & $4.21 \pm 1.70$ & $3.42 \pm 1.50$ & 0.080 \\
\hline Schober, $\mathrm{cm}$ & $12.99 \pm 1.61$ & $13.24 \pm 1.78$ & $12.60 \pm 1.26$ & 0.185 \\
\hline $\mathrm{FF}, \mathrm{cm}$ & $15.89 \pm 14.75$ & $13.07 \pm 14.54$ & $20.11 \pm 14.34$ & 0.057 \\
\hline $\mathrm{OCW}, \mathrm{cm}$ & $4.21 \pm 4.10$ & $3.56 \pm 3.41$ & $5.17 \pm 4.88$ & 0.285 \\
\hline VAS-pain, cm & $3.90 \pm 2.48$ & $3.00 \pm 2.21$ & $5.19 \pm 2.33$ & $0.017^{*}$ \\
\hline VAS-global, cm & $5.10 \pm 2.36$ & $3.73 \pm 1.85$ & $7.16 \pm 1.29$ & $0.000^{*}$ \\
\hline BASDAI & $3.85 \pm 2.41$ & $2.17 \pm 1.14$ & $6.37 \pm 1.38$ & $0.000^{*}$ \\
\hline HAQ-S & $1.05 \pm 0.74$ & $0.78 \pm 0.67$ & $1.44 \pm 0.68$ & $0.007^{*}$ \\
\hline BASFI & $3.51 \pm 2.91$ & $1.88 \pm 2.11$ & $5.96 \pm 2.10$ & $0.000^{*}$ \\
\hline $\mathrm{ESR}, \mathrm{mm} / \mathrm{h}$ & $30.31 \pm 23.97$ & $27.06 \pm 22.61$ & $35.18 \pm 25.64$ & 0.271 \\
\hline CRP, mg/l & $24.47 \pm 31.04$ & $20.04 \pm 28.01$ & $31.13 \pm 34.70$ & 0.104 \\
\hline \multicolumn{5}{|l|}{$\mathrm{BMD}, \mathrm{g} / \mathrm{cm}^{2}$} \\
\hline L2-L4 & $1.073 \pm 0.18$ & $1.080 \pm 0.17$ & $1.062 \pm 0.19$ & 0.626 \\
\hline Femur neck & $0.933 \pm 0.16$ & $0.975 \pm 0.14$ & $0.883 \pm 0.16$ & $0.032^{*}$ \\
\hline Total femur & $0.926 \pm 0.14$ & $0.962 \pm 0.11$ & $0.883 \pm 0.17$ & $0.044^{*}$ \\
\hline \multicolumn{5}{|l|}{ T score } \\
\hline L2-L4 & $-1.3 \pm 1.49$ & $-1.2 \pm 1.45$ & $-1.3 \pm 1.58$ & 0.723 \\
\hline Femur neck & $-0.8 \pm 1.15$ & $-0.6 \pm 0.99$ & $-1.1 \pm 1.27$ & 0.059 \\
\hline Total femur & $-1.0 \pm 1.08$ & $-0.8 \pm 0.77$ & $-1.3 \pm 1.32$ & $0.035^{*}$ \\
\hline SASSS & $20.10 \pm 14.57$ & $19.43 \pm 15.21$ & $21.05 \pm 13.96$ & 0.385 \\
\hline
\end{tabular}

FF = Finger-to-floor distance; OCW = occiput-to-wall distance; VAS-pain = visual analogue scale of pain; VAS-global = visual analogue scale of patient's assessment of global severity of disease; BASDAI = Bath Ankylosing Spondylitis Disease Activity Index; HAQ-S = Health Assessment Questionnaire - Spondyloarthropathies; BASFI = Bath Ankylosing Spondylitis Functional Index; SASSS = Stoke Ankylosing Spondylitis Spine Score. ${ }^{*} \mathrm{p}<0.05$, Mann-Whitney U test.

Statistical Analysis

Statistics Package for Social Sciences (SPSS Inc., Chicago, Ill., v. 16.0) was used for statistical analyses. Results are expressed as means \pm SD. Percent change in BMD at the spine and hip during the 24-month follow-up was calculated as: (BMD at 24 months - baseline BMD)/baseline BMD. Differences between active and remission groups at baseline were assessed using Mann-Whitney U test. Baseline and follow-up differences were assessed using Wilcoxon test. Pearson correlation coefficients were used to analyze the relationship between parameters. Twotailed $p$ values of $<0.05$ were considered statistically significant. Multivariate linear regression analysis was used to estimate the independent effects of some clinical and laboratory variables on BMD. Multicollinearity of independent parameters was analyzed using multicollinearity diagnostics tolerance value and variance inflation factor.

\section{Results}

Demographic, clinical and radiographic characteristics of the patients are shown in table 1 . Patients with active disease had significantly higher scores of patient's global assessment of disease activity-VAS (7.16 vs. 3.73), pain-VAS (5.19 vs. 3.00), BASDAI (6.37 vs. 2.17), Health Assessment Questionnaire - Spondyloarthropathies (1.44 vs. 0.78 ) and BASFI (5.96 vs. 1.88 ) than patients in remission (table 1). Patients with active disease had also significantly lower BMD at the hip (0.883 vs. $\left.0.962 \mathrm{~g} / \mathrm{cm}^{2}\right)$ than patients in remission. However, spinal BMD measurements were not different in both groups (1.062 vs. 1.080; table 1). Accordingly, frequency of osteopenia or osteoporosis concerning spinal T scores $(p>0.05)$ had a similar distribution between patients with active and inactive disease, whereas for higher frequency of osteope- 
Table 2. Multiple regression analysis of calculated values of age, body mass index, disease duration, Schober, BASDAI, BASFI, ESR, CRP and SASSS, with each index selected as an independent variable

\begin{tabular}{|c|c|c|c|c|c|c|c|c|c|c|c|c|}
\hline & \multicolumn{4}{|c|}{ L2-L4 BMD } & \multicolumn{4}{|c|}{ Femur neck BMD } & \multicolumn{4}{|c|}{ Total femur BMD } \\
\hline & SC & $\mathrm{p}$ value & tolera & VIF & SC & $\mathrm{p}$ value & tolera & VIF & SC & $\mathrm{p}$ value & tolera & VIF \\
\hline Age, years & -0.20 & 0.31 & 0.59 & 1.69 & -0.13 & 0.46 & 0.64 & 1.57 & 0.08 & 0.68 & 0.64 & 1.57 \\
\hline $\mathrm{BMI}, \mathrm{kg} / \mathrm{cm}^{2}$ & -0.02 & 0.93 & 0.56 & 1.78 & 0.19 & 0.31 & 0.58 & 1.72 & 0.01 & 0.96 & 0.58 & 1.72 \\
\hline DD, years & -0.16 & 0.50 & 0.44 & 2.26 & -0.13 & 0.53 & 0.48 & 2.08 & -0.05 & 0.81 & 0.48 & 2.08 \\
\hline BASDAI & -0.23 & 0.43 & 0.28 & 3.56 & 0.36 & 0.26 & 0.20 & 5.00 & 0.43 & 0.21 & 0.20 & 5.00 \\
\hline BASFI & 0.12 & 0.70 & 0.25 & 4.03 & $-0.69^{*}$ & $0.03^{*}$ & 0.21 & 4.84 & $-0.70^{*}$ & $0.04^{*}$ & 0.21 & 4.84 \\
\hline $\mathrm{ESR}, \mathrm{mm} / \mathrm{h}$ & 0.18 & 0.42 & 0.50 & 2.02 & -0.17 & 0.38 & 0.55 & 1.83 & -0.25 & 0.23 & 0.55 & 1.83 \\
\hline CRP, mg/l & -0.01 & 0.96 & 0.53 & 1.89 & 0.15 & 0.42 & 0.58 & 1.74 & 0.14 & 0.49 & 0.58 & 1.74 \\
\hline SASSS & 0.29 & 0.17 & 0.54 & 1.84 & -0.25 & 0.18 & 0.58 & 1.72 & -0.24 & 0.23 & 0.58 & 1.72 \\
\hline
\end{tabular}

SC = Standardized coefficients; VIF = variance inflation factor; DD = disease duration; BASDAI = Bath Ankylosing Spondylitis Disease Activity Index; BASFI = Bath Ankylosing Spondylitis Functional Index; SASSS = Stoke Ankylosing Spondylitis Spine Score. ${ }^{*} \mathrm{p}<0.05$.

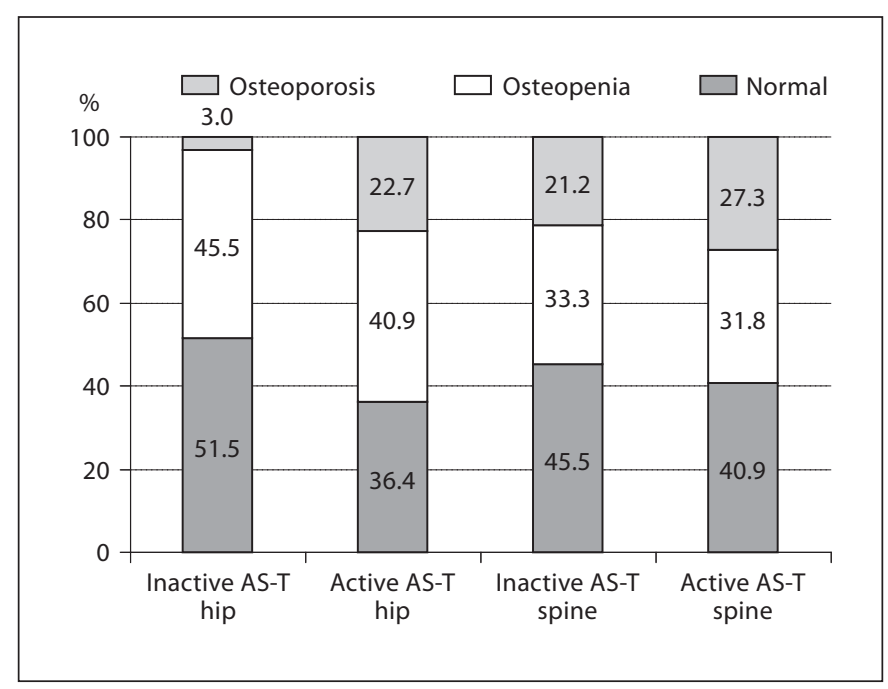

Fig. 1. Frequency of osteoporosis, osteopenia and normal BMD in patients with active or inactive disease, categorized according to T scores of hip or spinal measurements.

nia and osteoporosis concerning $\mathrm{T}$ scores of hip (0.035, $\mathrm{p}<0.05$; fig. 1).

All of the patients had normal levels of $25(\mathrm{OH}) \mathrm{D}$. None had deficiency $(<10 \mathrm{ng} / \mathrm{ml})$ or insufficiency $(<20$ $\mathrm{ng} / \mathrm{ml}$ ) for $25(\mathrm{OH}) \mathrm{D}$. The serum markers of bone metabolism (serum calcium, inorganic phosphate and alkaline phosphatase) were within the normal limits in all of the patients with AS. In patients, baseline levels for mean serum calcium level was $9.61 \pm 0.81 \mathrm{mg} / \mathrm{dl}$, mean serum inorganic phosphate level was $3.47 \pm 0.56 \mathrm{mg} / \mathrm{dl}$ and total serum alkaline phosphatase level was $107.06 \pm$ $28.00 \mathrm{U} / 1$.

Multiple regression analysis performed to determine independent effects of influencing factors on BMD in AS patients revealed no significant effect of age, body mass index, disease duration, lumbar Schober, BASDAI, ESR, CRP and SASSS on spinal or hip BMD measurements. However, BASFI had significant negative effect on hip BMD (table 2). Collinearity statistics revealed a lack of multicollinearity problem among the parameters tested.

Clinical data of patients $(n=21)$ who were included in the follow-up study are shown in table 3. Menopause did not occur in any of the female patients during follow-up. Age and disease duration were not significantly different in patients with active and those with inactive disease (table 4). Follow-up data revealed a $3.4 \%$ increase in spinal BMD but $0.9 \%$ and $0.25 \%$ decreases in femur neck $\mathrm{BMD}$ and total femur BMD, respectively, in the whole group after 24 months. A significant increase was observed in 7 (33\%) patients in spinal BMD and significant bone loss in 5 (23\%) patients in hip BMD. Spinal BMD significantly increased in both groups of patients who maintained an active or inactive disease during the course of follow-up, however only total femur BMD significantly decreased in patients with clinically inactive disease (table 3; fig. 2). The percent change in BMD values, SASSS 
Table 3. Patients' longitudinal data

\begin{tabular}{|c|c|c|c|c|c|c|}
\hline & \multicolumn{3}{|c|}{ Inactive $(\mathrm{n}=11)$} & \multicolumn{3}{|l|}{ Active $(\mathrm{n}=10)$} \\
\hline & baseline & 24 months & $\mathrm{p}$ & baseline & 24 months & $\mathrm{p}$ \\
\hline BMI, $\mathrm{kg} / \mathrm{m}^{2}$ & $24.93 \pm 4.60$ & $24.82 \pm 2.34$ & NS & $21.51 \pm 3.09$ & $22.61 \pm 3.63$ & NS \\
\hline $\mathrm{OCW}, \mathrm{cm}$ & $2.87 \pm 1.68$ & $1.28 \pm 1.54$ & NS & $3.20 \pm 2.38$ & $2.31 \pm 2.41$ & NS \\
\hline $\mathrm{FF}, \mathrm{cm}$ & $13.91 \pm 12.59$ & $17.26 \pm 14.92$ & NS & $21.62 \pm 18.25$ & $26.17 \pm 20.28$ & NS \\
\hline Chest expansion, $\mathrm{cm}$ & $4.54 \pm 2.68$ & $3.68 \pm 1.30$ & NS & $3.95 \pm 1.64$ & $3.43 \pm 0.75$ & NS \\
\hline Schober, $\mathrm{cm}$ & $13.25 \pm 2.18$ & $12.59 \pm 1.83$ & 0.050 & $12.57 \pm 1.20$ & $12.29 \pm 1.08$ & NS \\
\hline VAS-pain, cm & $3.08 \pm 1.20$ & $2.00 \pm 3.17$ & NS & $3.48 \pm 2.01$ & $3.26 \pm 2.65$ & NS \\
\hline HAQ-S & $0.60 \pm 0.61$ & $1.21 \pm 2.20$ & NS & $1.13 \pm 0.75$ & $1.37 \pm 0.89$ & NS \\
\hline VAS-global, cm & $3.85 \pm 1.74$ & $1.86 \pm 2.58$ & NS & $7.12 \pm 1.30$ & $5.73 \pm 2.19$ & NS \\
\hline BASFI & $2.12 \pm 2.28$ & $1.83 \pm 2.15$ & NS & $5.49 \pm 1.91$ & $3.75 \pm 3.00$ & NS \\
\hline $\mathrm{ESR}, \mathrm{mm} / \mathrm{h}$ & $20.78 \pm 15.50$ & $17.38 \pm 7.91$ & NS & $40.10 \pm 24.21$ & $29.83 \pm 16.77$ & NS \\
\hline CRP, mg/l & $19.14 \pm 18.11$ & $19.04 \pm 20.22$ & NS & $26.86 \pm 21.05$ & $34.29 \pm 39.56$ & NS \\
\hline \multicolumn{7}{|l|}{$\mathrm{BMD}, \mathrm{g} / \mathrm{cm}^{2}$} \\
\hline L2-L4 & $1.057 \pm 0.20$ & $1.088 \pm 0.22$ & 0.030 & $1.041 \pm 0.16$ & $1.085 \pm 0.18$ & 0.047 \\
\hline Femur neck & $0.947 \pm 0.17$ & $0.932 \pm 0.14$ & NS & $0.801 \pm 0.13$ & $0.793 \pm 0.13$ & NS \\
\hline Total femur & $0.922 \pm 0.12$ & $0.911 \pm 0.11$ & 0.009 & $0.822 \pm 0.15$ & $0.829 \pm 0.15$ & NS \\
\hline SASSS & $18.00 \pm 10.19$ & $20.36 \pm 10.53$ & 0.007 & $22.40 \pm 17.40$ & $25.80 \pm 17.78$ & 0.005 \\
\hline
\end{tabular}

FF = Finger-to-floor distance; VAS-pain = visual analogue scale of pain; HAQ-S = Health Assessment Questionnaire - Spondyloarthropathies; VAS-global = visual analogue scale of patient's assessment of global severity of disease; BASFI = Bath Ankylosing Spondylitis Functional Index; SASSS = Stoke Ankylosing Spondylitis Spine Score.

and Schober scores were similar in both groups (table 4). There was no significant relationship between percent changes in SASSS and BMD values.

\section{Discussion}

Our results showed that patients with ankylosing spondylitis continued to lose $\mathrm{BMD}$, which was detected at the hip measurements of DXA rather than spinal measurements. However, percent changes in BMD were not significantly different between patients with active and inactive disease. The frequency of having osteoporosis, osteopenia and normal BMD categorized according to $\mathrm{T}$ scores at the spine revealed a similar distribution between patients with active and inactive disease. However, for $\mathrm{T}$ scores at the hip, there was a shift towards increased frequency of osteoporosis in patients with active as compared to those with inactive disease (fig. 1). Spinal BMD significantly increased in both groups of patients with active and inactive disease. Although detrimental effects of active disease in AS has been considered to be more prominent at the spine, bone loss related to disease activity seemed to occur at the hip rather than spine. This is

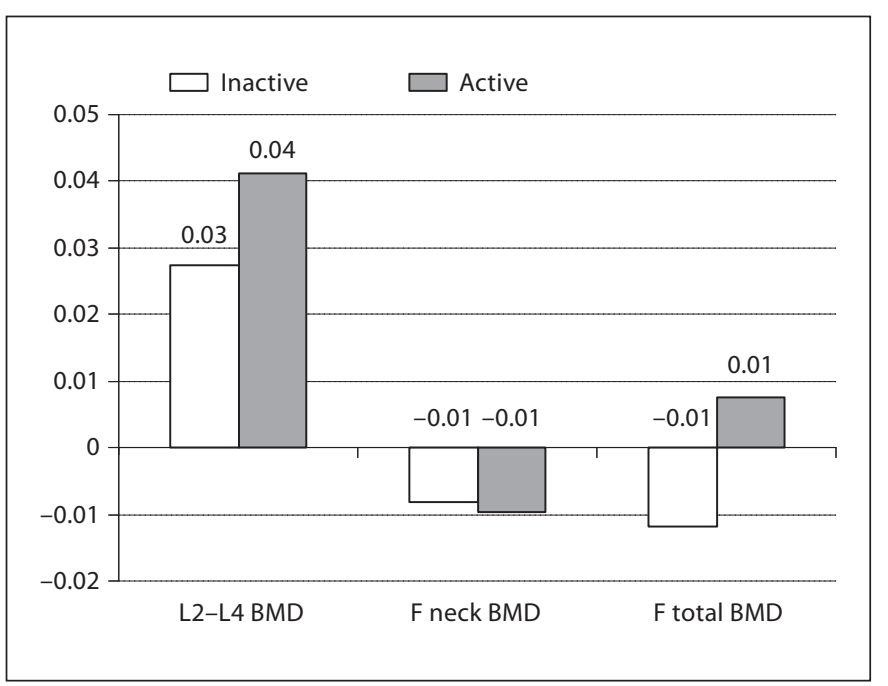

Fig. 2. Percent changes in BMD after 24 months in patients with active and inactive disease (all $\mathrm{p}>0.05$ ).

conceivable because detrimental effects of the disease activity present themselves with enthesitis of the vertebral margins, sclerosis of vertebral end-plates, syndesmophyte formation, interapophyseal joint and interpedicu- 
Table 4. Disease duration, age and percent changes in clinical parameters

\begin{tabular}{lrrr}
\hline & Inactive $(\mathrm{n}=11)$ & Active $(\mathrm{n}=10)$ & $\mathrm{p}$ \\
\hline $\begin{array}{l}\text { Disease duration, } \\
\quad \text { years }\end{array}$ & $13.18 \pm 10.62$ & $9.90 \pm 7.64$ & $\mathrm{NS}$ \\
Age, years & $37.27 \pm 6.87$ & $32.20 \pm 9.83$ & NS \\
SASSS, \% & $0.17 \pm 0.25$ & $0.26 \pm 0.24$ & NS \\
Schober, $\%$ & $-0.05 \pm 0.07$ & $-0.02 \pm 0.05$ & NS \\
BMD, \% & & & \\
$\quad$ L2-L4 & $0.027 \pm 0.02$ & $0.041 \pm 0.06$ & NS \\
$\quad$ Femur neck & $-0.008 \pm 0.06$ & $-0.009 \pm 0.04$ & NS \\
$\quad$ Total femur & $-0.011 \pm 0.01$ & $0.007 \pm 0.05$ & NS \\
\hline
\end{tabular}

SASSS $=$ Stoke Ankylosing Spondylitis Spine Score.

lar joint ankylosis that artificially increased DXA measurements.

Our data confirmed the previous studies that BMD measurements of the spine are unreliable in assessing osteoporosis [1, 3, 5, 6]. Accordingly, Donnelly et al. [4] showed lower BMD at the spine in patients with early AS compared to the patients with advanced disease, suggesting the role of syndesmophyte formation in artificial BMD increase at the spine. Lee et al. [6] reported that the BMD values in the late stage were higher with DXA and lower with quantitative CT. They decided that quantitative CT is more useful than an antero-posterior lumbar DXA in late-stage AS patients.

In some of the controlled studies, BMD at the spine and hip was reduced in AS compared to healthy controls but in mild disease rather than severe cases in whom spinal BMD has been reported to be similar to or higher than controls $[2-4,14,15]$. Two longitudinal studies in early AS have shown that spine and hip BMD decreased predominantly in patients with active disease [16, 17]. Maillefert et al. [16] showed decreased BMD at the femur neck but unchanged at the spine after 24 months of follow-up in AS excluding patients with syndesmophytes. The authors concluded that bone loss in their patient group was related to persistently elevated ESR, indicating the role of inflammation in bone loss. Similar observations have been suggested by Gratacos et al. [17] who found significant bone loss in AS patients with active disease. However, evaluating disease activity in AS is much more challenging with respect to other inflammatory arthritis due to the lack of a comprehensive relationship between laboratory variables (acute-phase reactants), clinical variables and imaging with the disease process $[18,19]$.
In this study we found that BMD increases in both active and inactive patients in the lumbar spine, which was in contrast to the results of Maillefert et al. [16] who reported unchanged BMD in the lumbar spine and Gratacos et al. [17] who reported significant loss at lumbar spine in patients with early active disease. Our study revealed significant loss in femur BMD in the inactive patient group in contrast to the results of Gratacos et al. [17] and Maillefert et al. [16] who reported significant bone loss in the femur BMD in active patients. This discrepancy between results may be related to the fact that the previous studies used CRP or ESR whereas we used BASDAI as the disease activity criteria for a sustained remission or active disease during follow-up. BASDAI is a composite index to better estimate sustained disease activity or inactivity during follow-up. BASDAI scores also make it possible to evaluate and score spinal pain and stiffness, which was highly important to understand the effect of disease activity on BMD at measured sites.

The etiology of osteoporosis in AS is still not clear. Inflammatory activity and mediators certainly have significant roles in the development and maintenance of BMD loss in AS. It has been suggested that local or systemic inflammatory cytokine release might be implicated in bone loss. This bone loss could be related to an increase in bone resorption and correlations have been established between some biochemical markers of bone resorption on one hand, and ESR and CRP level on the other $[17,20]$. Among factors which can influence bone resorption and osteoclast activity, TNF $\alpha$ plays a prominent role [21]. Other probable pathogenetic mechanisms are genetic predisposition and impaired calcium and vitamin $\mathrm{D}$ absorption related to chronic inflammatory intestinal lesions [22]. Gratacos et al. suggested the role of IL-6, and increased BMD with anti-TNF treatment has been reported, indicating the role of inflammatory cytokines in BMD loss in AS $[17,21,23]$. On the other hand, immobility and decreased physical activity also have an important role in the development of osteoporosis in chronic diseases. Our study revealed a significant negative relationship between BASFI and BMD in AS patients, which indicated a decisive role for mobility.

Regular use of some NSAIDs has been suggested to be related to higher BMD in males and females in vivo [2426]. These drugs inhibit prostaglandin synthesis, which has anabolic effects on bone [24-26]. Sixteen patients (76\%) continued NSAIDs during the 24-month follow-up period in our study. However, our data was inconclusive on the effect of NSAID use on BMD. 


\section{Conclusion}

Significant increases in spine BMD in parallel with increased SASSS revealed that prominent spinal involvement with new bone formation, sclerosis and syndesmo- phytes may influence spinal BMD measurements using DXA methods in AS. Proximal femur measurements seem to be less affected by disease-related new bone formation.

\section{References}

$>1$ Singh A, Bronson W, Walker SE, Allen SH: Relative value of femoral and lumbar bone mineral density assessments in patients with ankylosing spondylitis. South Med J 1995;88: 939-943.

$>2$ Will R, Palmer R, Bhalla AK, Ring F, Calin A: Osteoporosis in early ankylosing spondylitis: a primary pathological event? Lancet 1989;2:1483-1485.

>3 Devogelaer JP, Maldague B, Malghem J, Nagant de Deuxchaisnes C: Appendicular and vertebral bone mass in ankylosing spondylitis. A comparison of plain radiographs with single- and dual-photon absorptiometry and with quantitative computed tomography. Arthritis Rheum 1992;35:1062-1067.

-4 Donnelly S, Doyle DV, Denton A, Rolfe I, McCloskey EV, Spector TD: Bone mineral density and vertebral compression fracture rates in ankylosing spondylitis. Ann Rheum Dis 1994;53:117-121.

$>5$ El Maghraoui A, Borderie D, Cherruau B, Edouard R, Dougados M, Roux C: Osteoporosis, body composition, and bone turnover in ankylosing spondylitis. J Rheumatol 1999; 26:2205-2209.

-6 Lee YS, Schlotzhauer T, Ott SM, van Vollenhoven RF, Hunter J, Shapiro J, Marcus R, McGuire JL: Skeletal status of men with early and late ankylosing spondylitis. Am J Med 1997;103:233-241.

$>7$ Kim HR, Kim HY, Lee SH: Elevated serum levels of soluble receptor activator of nuclear factors-kappaB ligand (sRANKL) and reduced bone mineral density in patients with ankylosing spondylitis (AS). Rheumatology (Oxford) 2006;45:1197-1200.

8 World Health Organization Study Group: Assessment of fracture risk and its application to screening for postmenopausal osteoporosis. Geneva, WHO, 1994.

$>9$ Van der Linden S, Valkenburg HA, Cats A: Evaluation of diagnostic criteria for ankylosing spondylitis: a proposal for modification of the New York criteria. Arthritis Rheum 1984;27:361-368.
10 Garrett S, Jenkinson T, Kennedy LG, Whitelock H, Gaisford P, Calin A: A new approach to defining disease status in ankylosing spondylitis: the Bath Ankylosing Spondylitis Disease Activity Index. J Rheumatol 1994; 21:2286-2291.

11 Daltroy LH, Larson MG, Roberts NW, Liang MH: A modification of the Health Assessment Questionnaire for the spondyloarthropathies. J Rheumatol 1990;17:946-950.

12 Calin A, Garrett S, Whitelock H, Kennedy LG, O’Hea J, Mallorie P, Jenkinson T: A new approach to defining functional ability in ankylosing spondylitis: the development of the Bath Ankylosing Spondylitis Functional Index. J Rheumatol 1994;21:2281-2285.

13 Averns HL, Oxtoby J, Taylor HG, Jones PW, Dziedzic K, Dawes PT: Radiological outcome in ankylosing spondylitis: use of the Stoke Ankylosing Spondylitis Spine Score (SASSS). Br J Rheumatol 1996;35:373-376.

14 Mullaji AB, Upadhyay SS, Ho EK: Bone mineral density in ankylosing spondylitis. DEXA comparison of control subjects with mild and advanced cases. J Bone Joint Surg Br 1994;76:660-665.

15 Karberg K, Zochling J, Sieper J, Felsenberg $\mathrm{D}$, Braun J: Bone loss is detected more frequently in patients with ankylosing spondylitis with syndesmophytes. J Rheumatol 2005;32:1290-1298.

16 Maillefert JF, Aho LS, El Maghraoui A, Dougados $\mathrm{M}$, Roux C: Changes in bone density in patients with ankylosing spondylitis: a twoyear follow-up study. Osteoporos Int 2001; 12:605-609.

- 17 Gratacos J, Collado A, Pons F, Osaba M, Sanmarti R, Roque M, Larrosa M, MunozGomez J: Significant loss of bone mass in patients with early, active ankylosing spondylitis: a follow up study. Arthritis Rheum 1999; 42:2319-2324.

18 Spoorenberg A, van der Heijde D, de Klerk E, Dougados M, de Vlam K, Mielants H, van der Tempel H, van der Linden S: Relative value of erythrocyte sedimentation rate and Creactive protein in assessment of disease activity in ankylosing spondylitis. J Rheumatol 1999;26:980-984.
19 Ozgocmen S, Godekmerdan A, OzkurtZengin F: Acute-phase response, clinical measures and disease activity in ankylosing spondylitis. Joint Bone Spine 2007;74:249253.

20 Toussirot E, Ricard-Blum S, Dumoulin G, Cedoz JP, Wendling D: Relationship between urinary pyridinium cross-links, disease activity and disease subsets of ankylosing spondylitis. Rheumatology (Oxford) 1999; 38:21-27.

21 Demis E, Roux C, Breban M, Dougados M: Infliximab in spondylarthropathy: influence on bone density. Clin Exp Rheumatol 2002;20:S185-S186.

-22 Ardizzone S, Bollani S, Bettica P, Bevilacqua M, Molteni P, Bianchi Porro G: Altered bone metabolism in inflammatory bowel disease: there is a difference between Crohn's disease and ulcerative colitis. J Intern Med 2000;247: 63-70.

-23 Allali F, Breban M, Porcher R, Maillefert JF, Dougados M, Roux C: Increase in bone mineral density of patients with spondyloarthropathy treated with anti-tumour necrosis factor alpha. Ann Rheum Dis 2003;62:347349 .

24 Carbone LD, Tylavsky FA, Cauley JA, Harris $\mathrm{TB}$, Lang TF, Bauer DC, Barrow KD, Kritchevsky SB: Association between bone mineral density and the use of nonsteroidal anti-inflammatory drugs and aspirin: impact of cyclooxygenase selectivity. J Bone Miner Res 2003;18:1795-1802.

25 Morton DJ, Barrett-Connor EL, Schneider DL: Nonsteroidal anti-inflammatory drugs and bone mineral density in older women: the Rancho Bernardo study. J Bone Miner Res 1998;13:1924-1931.

26 Bell NH, Hollis BW, Shary JR, Eyre DR, Eastell R, Colwell A, Russell RG: Diclofenac sodium inhibits bone resorption in postmenopausal women. Am J Med 1994;96:349-353. 